\title{
Ten Years of Sourcery at CAMS/LLNL- Evolution of a Cs Ion Source
}

\author{
J. Southon and M. Roberts.
}

This article was submitted to

$8^{\text {th }}$ International Conference on Accelerator Mass Spectrometry Vienna, Austria

September 6-10, 1999

\section{October 7, 1999}

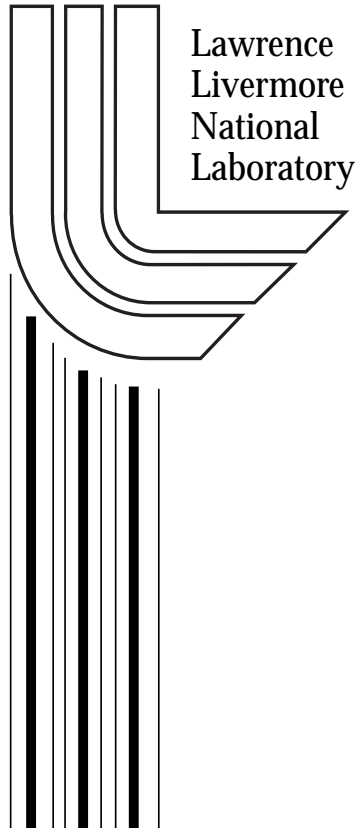




\section{DISCLAIMER}

This document was prepared as an account of work sponsored by an agency of the United States Government. Neither the United States Government nor the University of California nor any of their employees, makes any warranty, express or implied, or assumes any legal liability or responsibility for the accuracy, completeness, or usefulness of any information, apparatus, product, or process disclosed, or represents that its use would not infringe privately owned rights. Reference herein to any specific commercial product, process, or service by trade name, trademark, manufacturer, or otherwise, does not necessarily constitute or imply its endorsement, recommendation, or favoring by the United States Government or the University of California. The views and opinions of authors expressed herein do not necessarily state or reflect those of the United States Government or the University of California, and shall not be used for advertising or product endorsement purposes.

This is a preprint of a paper intended for publication in a journal or proceedings. Since changes may be made before publication, this preprint is made available with the understanding that it will not be cited or reproduced without the permission of the author.

This report has been reproduced directly from the best available copy.

Available to DOE and DOE contractors from the

Office of Scientific and Technical Information

P.O. Box 62, Oak Ridge, TN 37831

Prices available from (423) 576-8401

http:/ / apollo.osti.gov/bridge/

Available to the public from the National Technical Information Service

U.S. Department of Commerce 5285 Port Royal Rd., Springfield, VA 22161 http://www.ntis.gov/

OR

Lawrence Livermore National Laboratory Technical Information Department's Digital Library http://www.llnl.gov/tid/Library.html 


\title{
Ten years of sourcery at CAMS/LLNL - evolution of a Cs ion source
}

\author{
John Southon, Mark Roberts \\ Center for AMS, L-397, Lawrence Livermore National Lab, Livermore CA 94550 USA
}

\begin{abstract}
The present performance and status of the LLNL AMS ion source and the rationale for the series of changes which led to the present design are discussed
\end{abstract}

\section{Introduction}

In 1989 a prototype General Ionex Corp. Model 846 high-intensity multi-sample source was installed at the Center for AMS, Lawrence Livermore National Laboratory (CAMS). Modifications to the original design were made during installation [1], and a second generation sample changer was installed in 1993 [2]. The design has been further modified over the past decade to improve reliability, increase output, and reduce sample to sample memory, and four sources are now operating on three AMS systems within CAMS. We describe how the present design has evolved through changes which are potentially applicable to other AMS ion sources, particularly those based on the 846 design.

\section{The GIC 846 design - problem areas}

The original 846 (Fig. 1) represented a major improvement in terms of output and ease of operation over most AMS sources available at the time, but had significant design problems. The sample changer frequently dropped and/or failed to retract samples, its electronics were sensitive to sparks, and wheel changes were awkward due to the design of the wheel, hub, and enclosing chamber. The volume around the sample was poorly pumped due to small clearances between the immersion lens and ionizer assembly, to the extent that the source intially exhibited significant sample-to-sample memory for carbon. (This gap was also prone to arcing and shorting out). Pumping on the sample wheel chamber and the extraction region was also poor. The cathode and extraction insulators 
were inadequately shielded and rapidly became dirty, and the length of the extraction insulator was marginal for $30-40 \mathrm{kV}$ operation. The Cs feed tube ran cool and was prone to clogging. The source body, sample wheel, and the wheel chamber housing were all made of $\mathrm{Al}$ and were difficult to clean and subject to corrosion by $\mathrm{Cs}$ when exposed to air.

\section{LLNL modifications}

\subsection{General}

The modification program aimed to: i) improve reliability and ease of maintenance, ii) increase output, and iii) reduce sample to sample memory. In summary, i) was largely accomplished by a complete redesign of the sample changer [2], proper shielding of insulators, increasing clearances across high voltage gaps, and rebuilding the source body and sample wheel chamber from stainless steel for ease of cleaning; ii) was mostly brought about by improvements to vacuum and by changes which allowed operation at higher sputtering voltages; and iii) was primarily due to provision of better pumping and improved thermal isolation of critical components around the sample .

\subsection{Vacuum}

Improvements in the source and injection line vacuum have consistently resulted in higher output, presumably from decreased losses of negative ions by stripping to neutrals in interactions with residual gas. We improved pumping around the sample by increasing the clearance between the ionizer assembly and immersion lens from 1.5 to $5 \mathrm{~mm}$ (compare Figs. 1 and 2), and slotting the sides of the immersion lens snout (Fig. 3). The supports for the ionizer assembly and the ground electrode of the extraction assembly were each reduced to three thin ribs to improve pumping around the ionizer baseplate and in the extraction region (Figs 2 and 4). As reported previously [3], switching from a 500 1/s turbmolecular pump to a 20001/s CTI Cryo-Torr 8 reduced pressures by a factor of 3 , 
increased source outputs by $20-30 \%$, and reduced pumpdown times after wheel changes and source maintenance by $30-40 \%$.

\subsection{Thermal isolation.}

The geometry changes for better pumping also improved the thermal isolation of the immersion lens, the ionizer baseplate and the extraction ground electrode, and increased their operating temperatures. It is our philosophy that source components should run very cool to condense high-vapor pressure materials and prevent sample-to-sample memory, or very hot, so that stray neutrals are rapidly re-evaporated or baked to a refractory coating (see also [4]). Better thermal isolation of the ionizer assembly also reduces the required ionizer power and thus the total thermal load on the source.

\subsection{Insulators.}

Extraction and cathode insulator shields were installed, mounted from the upstream end of the insulators and overlapping their entire length (Fig 2). The length of the extraction insulator was increased to allow 40kV operation. (In the new High Voltage Engineering Europa version of the 846, two old style insulators are stacked to obtain the same effect).

\subsection{Higher cathode voltages}

Operation at higher sputtering voltages $(10-11 \mathrm{kV}$ vs $8 \mathrm{kV}$ initially) has been a major factor in achieving higher outputs. Two essential changes were increasing the immersion lens - ionizer assembly clearance as described above, and proper shielding of the cathode insulator. Operating at high cathode voltages requires good electron supression to avoid heavy X-ray loading and prevent cathode or extraction current runaway. Samples in our source are recessed into $1.2 \mathrm{~mm}$ diameter holes in the sample holders (by one diameter), and this probably contributes to good electron suppression. 


\subsection{Cs feed.}

The Cs feed tube was redesigned as a rigid double-walled tube with vacuum insulation. The reservoir and feed tube assembly screws by hand on to a hollow screw on the ionizer assembly (Figs 2 and 4). A new reservoir for a larger (5g) Cs charge, built around a $20 \mathrm{~mm}$ Conflat nipple, was installed to reduce the frequency of Cs changes.

After years of successful operation, the original single-jet Cs feed (Fig 1) abruptly began producing a keyhole-shaped Cs spot when the ion source was set up on a new injection line. Electrostatics calculations showed that the off-axis lobe was due to Cs ions produced on the cylindrical surface of the central ionizer hole, but we can only speculate on what produced this sudden change: better source vacuum, lower reservoir temperatures? The problem was cured by replacing the single-jet feed which pointed directly at this hole with a version having 6 jets aimed at the spherical ionizer surface (Figs 2 and 4).

\section{Present performance}

Source parameters are summarized in Table 1. Note the following additional details: $\quad$ Cs currents are determined using a sample holder converted into a Faraday Cup by drilling the rear ram insertion hole deeper to connect with the sample hole (R.Middleton, pers. comm.).

The Cs spot diameter on the sample can be varied by altering the longitudinal sample position. We run with the sample back from the optimum Cs focus, so the divergent Cs beam sputters the sample efficiently as it burns deeper.

Sample conversion efficiencies are calculated by comparing measured ${ }^{14} \mathrm{C}$ counts

or ${ }^{13} \mathrm{C}$ charge with the known quantities of isotope originally present in the sample, taking into account the source to detector transmission efficiency of $50 \%$. Conversion efficiencies vary, but the $10 \%$ value has been found for samples ranging from $1 \mathrm{mg}$ to $60 \mu \mathrm{g}$ of carbon.

Beam emittance is measured approximately using beam scanners and slits in the injection beamline. The value given corresponds to the outer edges of the beam (ca. 95- 
$98 \%$ of total intensity) and represents a divergence of 30mrad and an equivalent spot radius of $1.3 \mathrm{~mm}$ looking back at the source. Note that the beam characteristics change significantly as the source warms up to full output.

\section{Where is the next $100 \mu \mathrm{A}$ ?}

It is widely believed that sample overheating is a limiting factor on source output, and that the intense outputs available from single-sample sources [5] are due to better sample cooling. Since our sample holders are heated sufficiently at 10 or $11 \mathrm{kV}$ cathode voltage to inflict burns when initially removed from the source, we tested this hypothesis by replacing the sample changer and gate valve with a coaxially water cooled single-sample cathode rod which provided excellent sample cooling. Tests showed no improvement in $\mathrm{C}^{-}$ output over the multi-sample version; nor did the output drop when cathode cooling (other than convection to air) was completely cut off. We suggest that the sample cooling effect is real, but less important than previously thought. This conclusion is supported by the observation that increasing cathode voltages to 14 or $15 \mathrm{kV}$ improves $\mathrm{C}^{-}$output still further in spite of increased sample heat loads (though outputs from refractory sample materials like $\mathrm{Al}_{2} \mathrm{O}_{3}$ or $\mathrm{BeO}$ do indeed drop).

Another possibility is that space charge limits the efficiency with which $\mathrm{Cs}^{+}$can be pulled off the ionizer surface, and/or the extraction of negative ions from the sample holder. Electrostatics calculations and experimental modifications which support this theory and point the way to further increases in output are described elsewhere [6].

\section{Acknowledgements.}

This work was performed under the auspices of the US DOE at LLNL under contract W-7405-Eng-48. We thank Jack Garibaldi, Jim Hay, Bear Hornady, Paul Norman, Randy Leber, and our late colleague Ivan Proctor, for their contributions. 


\section{References}

[1] I.D.Proctor et al., The LLNL ion source - past, present, and future, Nucl. Instr. and Meth. B52, (1990) 334.

[2] M.L.Roberts et al., The new LLNL AMS sample changer, Nucl. Instr. and Meth. B92, (1994) 111.

[3] M.Roberts et al., The LLNL AMS facility, Nucl. Instr, and Meth. B123 (1997) 57

[4] V.R.Kovslowsky, H.R.Andrews, W.G.Davies, Y.Imahori and M.Bolusmjak, The reduction of sample memory effects in the Chalk River AMS ion source, Nucl. Instr. and Meth. B123 (1997) 226

[5] R.Middleton, Highlights of ion-source development at the University of Pennsylvania, Workshop on Techniques in AMS, Oxford (June 30-July 1, 1986), R.E.M.Hedges and E.T.Hall eds, Oxford Radiocarbon Acelerator Unit, 1987, p82.

[6] T.Brown, M.L.Roberts and J.R.Southon, Ion source modeling and improved performance of the CAMS high-intensity Cs-sputter ion source, these proceedings. 


\section{Table 1. LLNL ion source characteristics}

\section{Typical operating settings.}

Extraction voltage $\quad 40 \mathrm{kV}(50 \mathrm{kV}$ with longer extraction insulator)

Cathode voltage $\quad 10-11 \mathrm{kV}(3 \mathrm{kV}$ for low melting-point samples: $\mathrm{Cl}$, I etc)

Ionizer power $\quad 135 \mathrm{~W}$

Cs reservoir temp approx. $150^{\circ} \mathrm{C}$

Cathode currents $3-4 \mathrm{~mA}(1 \mathrm{~mA}$ resistive bleed, $1.5 \mathrm{~mA} \mathrm{Cs}, 1.5 \mathrm{~mA}$ electrons)

Cs spot diameter $\quad .6$ to $1.2 \mathrm{~mm}$ (depends on sample position)

Outputs $\quad 200-250 \mu \mathrm{A} \mathrm{C}^{-}(\mathrm{C}$ on $\mathrm{Fe}), 10-15 \mu \mathrm{A} \mathrm{BeO}^{-}\left(\mathrm{BeO}^{-}\right.$plus $\left.\mathrm{Nb}\right)$

Efficiency $\left(\mathrm{C}^{-}\right.$to $\left.\mathrm{C}^{-}\right) \quad 4-10 \%$

Emittance (approx.) $\quad 40 \pi \mathrm{mm}-\mathrm{mrad}$ at $40 \mathrm{keV}$ extraction, $10 \mathrm{kV}$ cathode, $200 \mu \mathrm{A} \mathrm{C}^{-}$

\section{Sample changing, maintenance, etc.}

Sample change time $3 \mathrm{sec}$ (next sample), $15 \mathrm{sec}$ (180 ${ }^{\circ}$ sample wheel rotation)

Wheel change $\quad 15$ minutes (minimum beam off to beam on time )

Full source cleaning 3 hours (minimum beam off to beam on time)

Cs charge lifetime $\quad 2-3$ months $(5 \mathrm{~g})$

Ram bellows 3-4 months (20-40,000 cycles)

lifetime 


\section{Figure captions.}

Fig. 1. The orginal GIC846 source design. a) extraction (ground) electrode, b) extraction insulator, c) cathode insulator, d) ionizer and Cs beam-forming electrode, e) immersion lens and sample holder, f) Cs reservoir and feed tube

Fig. 2. The present LLNL source.

Fig. 3. The cathode assembly with the immersion lens snout removed. The micrometers are used to reposition the cathode to compensate for any small misalignments in mounting a new ionizer.

Fig. 4. The sample body, ionizer, Cs reservoir and Cs feed/beam-forming electrode. The boxes on either side of the source body contain electron suppression magnets which produce a transverse field of 40 gauss at the source centerline. 


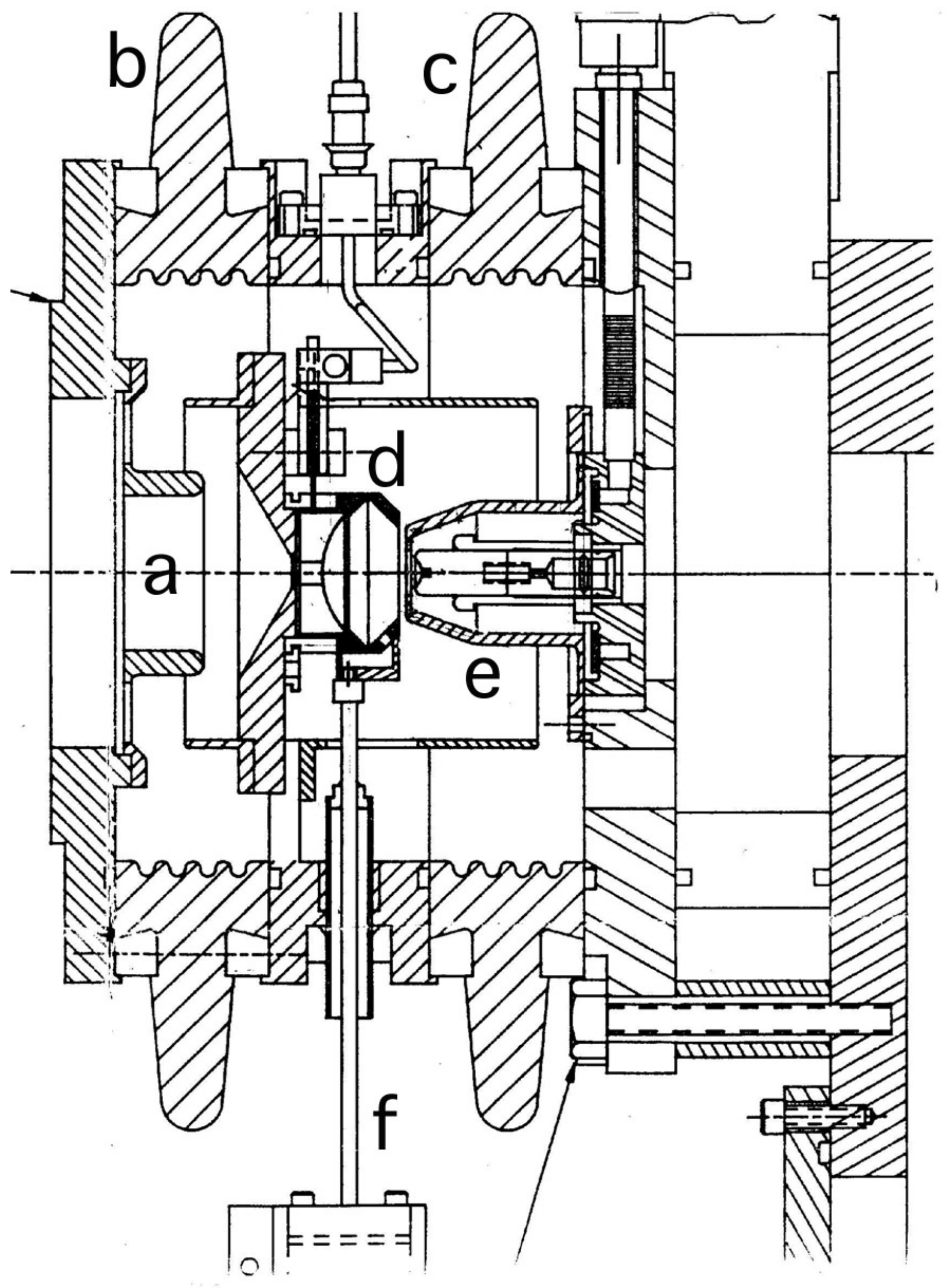




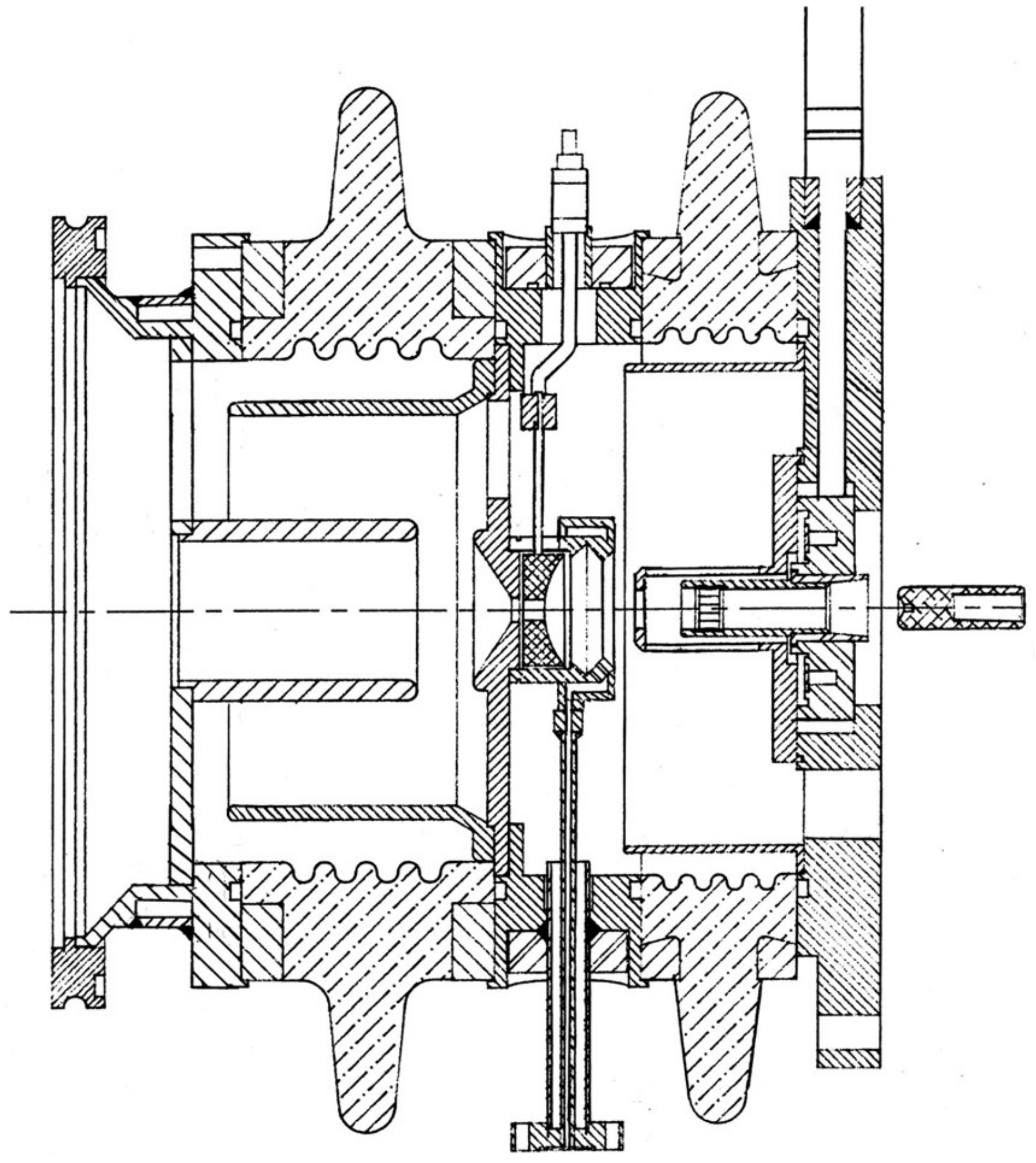




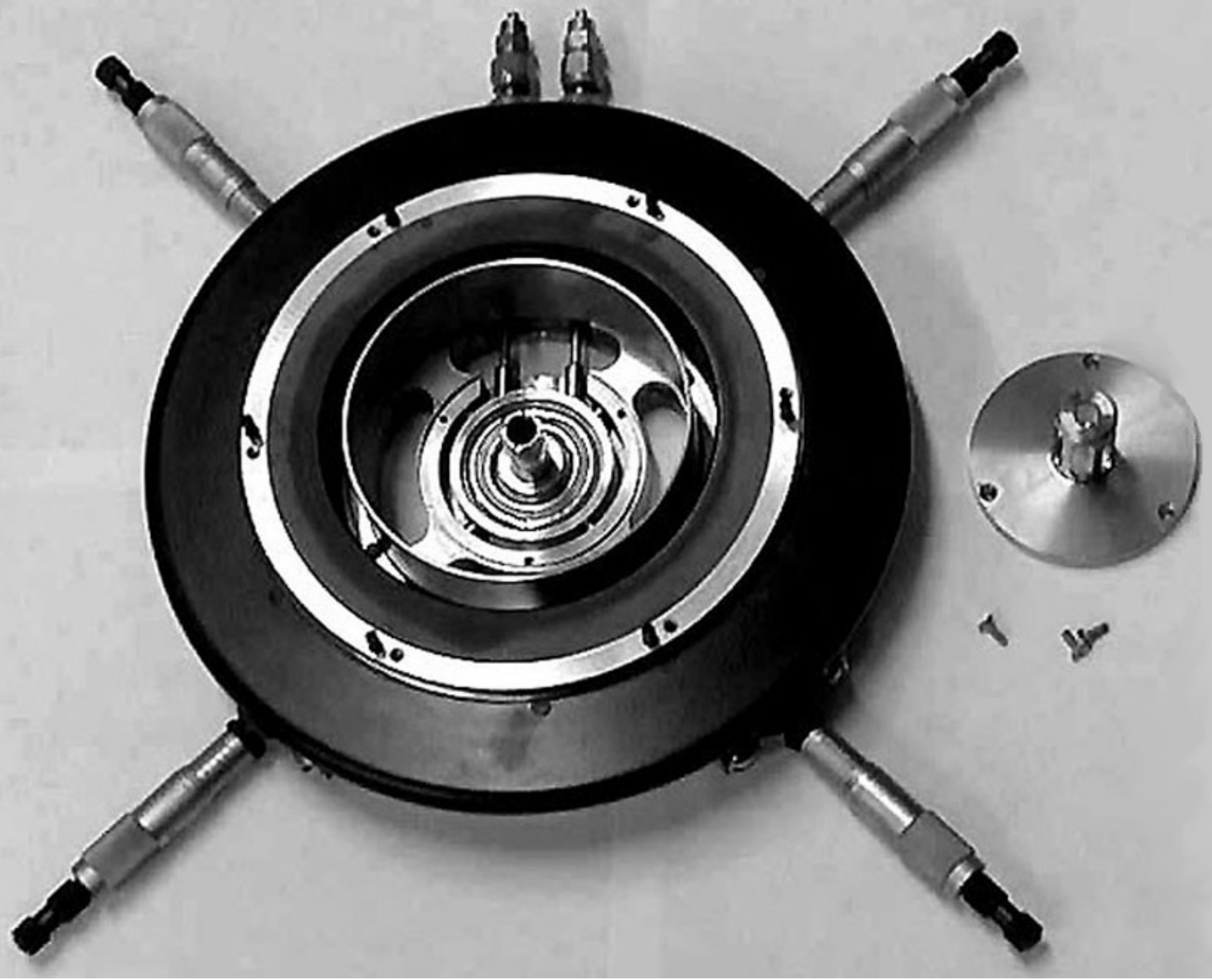




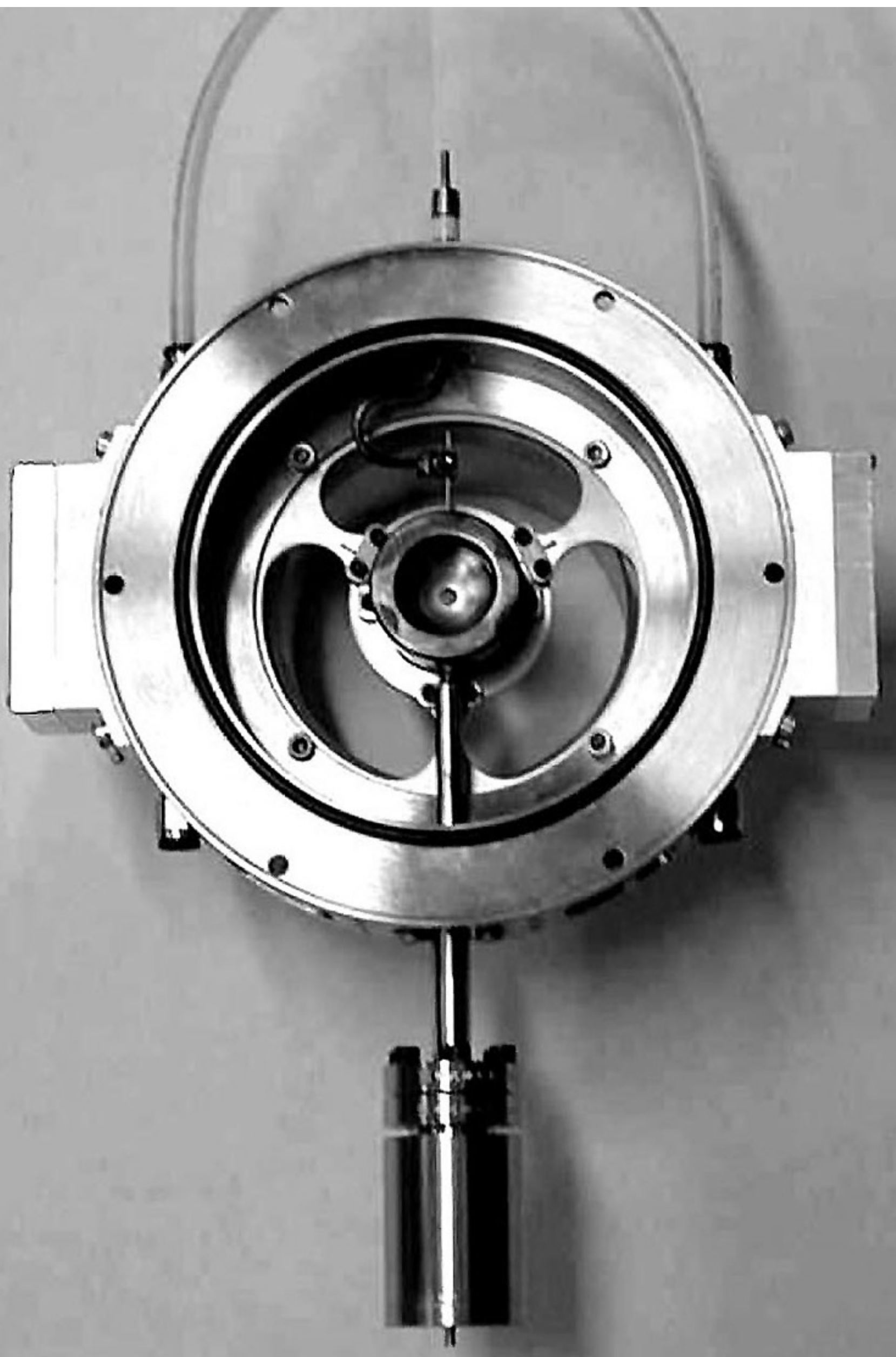

